\title{
Historia archivística de los expedientes de censura editorial (1942-2017)
}

\author{
Daniel Gozalbo Gimeno \\ Archivo General de la Administración
}

Título: Historia archivística de los expedientes de censura editorial (1942-2017).

Resumen: El presente artículo pasa revista a la historia de los expedientes de censura editorial en España desde que empezaron a gozar de tratamiento archivístico durante el verano de 1942. Se da noticia también del personal que formaba parte del Archivo General de la Vicesecretaría de Educación Popular y sus diversas secciones y metamorfosis hasta la Transición.

Palabras clave: Archivo, Censura editorial, Franquismo.

Fecha de recepción: 7/12/2017.

Fecha de aceptación: 28/12/2017.
Title: History of the Files of Editorial Censorship (1942-2017).

Abstract: This article reviews the history of the files of editorial censorship in Spain since they began to deserve archival treatment during the summer of 1942. News is also given of the staff that was part of the Archivo General de la Vicesecretaría de Educación Popular and its various sections and metamorphoses until the Transition.

Key words: Archive, Editorial Censorship, Francoism.

Date of Approval: 28/12/2017.

Los expedientes de censura de libros o publicaciones no periódicas que desde sus inicios generó el Régimen franquista pudieron haber desaparecido, expurgados como tantas otras series documentales que saturaban los estantes de las oficinas de la Censura. Sin embargo, y por fortuna, han llegado hasta nosotros, formando un corpus de varios centenares de miles de expedientes que representan una fuente fundamental para el estudio de la producción literaria y su control y orientación gubernativa en España 
durante el siglo XX. En la actualidad se conservan en el Archivo General de la Administración de Alcalá de Henares, a disposición de quien desee consultarlos.

Estos expedientes no comenzaron a gozar de un tratamiento archivístico específico hasta el verano de 1942, cuando se creó un servicio de archivo en la Vicesecretaría de Educación Popular de la Secretaría General del Movimiento, a cargo de un miembro del Cuerpo Facultativo de Archiveros y Bibliotecarios. El hecho, nada caprichoso en un período de fortísima escasez de medios para casi todo, y especialmente para la dotación de Archivos, respondía a las necesidades creadas desde el inicio de la Guerra Civil por la galopante generación de documentos administrativos por parte de la Censura en sus distintos niveles de actuación (editorial, teatral, cinematográfica, de prensa, de espectáculos, de plástica, etc.).

La censura de la producción editorial toma carta de naturaleza en el bando sublevado desde los mismos comienzos de la Guerra Civil, pero no se identifica una institución centralizadora de dicha función gubernativa hasta el Decreto de 14 de enero de $1937^{1}$, que crea la Delegación del Estado para Prensa y Propaganda, y la Orden de 29 de mayo de $1937^{2}$, que le atribuye plenas competencias en materia de censura libraria ${ }^{3}$. A partir de ese momento, la maquinaria burocrática, ubicada en instituciones de diverso nombre y adscripción administrativa, no cesará en la producción de expedientes hasta su extinción definitiva en $1983^{4}$. Desde 1937 a 1942 las instituciones que se hicieron cargo de la censura de libros fueron: 1) la

1 BOE, no 89, de 17 de enero de 1937.

2 BOE, no 226, de 3 de junio de 1937.

3 Justamente, el informe del primer expediente que abre la gran serie administrativa de la Censura Editorial conservada en el Archivo General de la Administración (AGA) se dató el 16 de junio de 1937. Se trata del expediente con número 1-37, correspondiente a la obra Páginas de gloria de la marina nacional, de Francisco Vallés Collantes: AGA, Cultura, caja 21/06750.

4 Si bien hay que precisar que la censura como pesquisa de transgresión de los principios ideológicos del régimen establecido se extingue formalmente con el Real Decreto-ley 24/1977, de 1 de abril, sobre libertad de expresión. A partir de ese momento pervive de forma inercial una práctica administrativa de depósito de ejemplares que desaparecerá algunos años después. La primera oficina de censura se instaló en 1937 en Salamanca, pasando después a Burgos y, finalmente, tras la derrota republicana, a Madrid. 
Delegación del Estado para Prensa y Propaganda, ya citada, dependiente de la Secretaría General del Jefe del Estado; 2) el Servicio Nacional de Propaganda del Ministerio del Interior5; 3) el Servicio Nacional de Propaganda del Ministerio de la Gobernación, que se convierte en Dirección General a partir de agosto de $1939^{6}$; y 4) la Delegación Nacional de Propaganda de la Vicesecretaría de Educación Popular, dependiente de la Secretaría General del Movimiento ${ }^{7}$.

En el momento de la creación de su Archivo, en julio de 1942, la Vicesecretaría de Educación Popular se estructuraba en dos grandes Delegaciones Nacionales, una de Prensa y otra de Propaganda, de las que dependían diversas secciones encargadas de funciones específicas. La Delegación Nacional de Prensa tenía a su cargo el control total de la actividad periodística y de las publicaciones periódicas editadas en España y de las llegadas del extranjero; por su parte, la Delegación Nacional de Propaganda asumía un abanico de competencias más variado, entre las que destacan la censura de libros o ediciones no periódicas, el control de las producciones cinematográficas ${ }^{8}$, el teatro, la radio, las producciones plásticas, los discos de música y las conferencias y actos públicos. Una panoplia de actividades tan vasta suponía lógicamente la generación de

5 Ley de organización de la Administración General del Estado (30 de enero de 1938): BOE, no 467, de 31 de enero de 1938.

6 Ley de 29 de diciembre de 1938, modificando la anterior: BOE, $\mathrm{n}^{\circ} 183$, de 31 de diciembre de 1938.

7 Ley de 20 de mayo de 1941, por la que se transfieren los Servicios de Prensa y Propaganda a la Vicesecretaría de Educación de FET y de las JONS, creada por esta ley: BOE, no 142, de 22 de mayo de 1941. El AGA custodia, junto a la gran serie de Censura Editorial, un conjunto documental complementario en forma de circulares, informes y correspondencia que permite profundizar en el entramado normativo y organizativo de estas instituciones, accesible a través del inventario general IDD (03)049.001, muy utilizado por la historiografía especializada en este ramo. Esta normativa, de perfil bajo y consumo interno, es de gran utilidad para comprender los mecanismos de funcionamiento de la censura de libros, dado que, diversamente a lo que sucede con la prensa, no existirá una disposición de rango de ley que reglamente este sector hasta la promulgación de la Ley 14/1966 de Prensa e Imprenta (18 de marzo): BOE, no 67, de 19 de marzo de 1966.

8 La gran influencia del cine sobre las masas hará desgajar de Propaganda una Delegación Nacional de Cinematografía y Teatro, plenamente activa en el mismo año 1942. 
ingentes cantidades de documentos y, por consiguiente, la necesidad de implementación de un sistema de gestión documental fundamentado en un archivo que diera escape periódico a los flujos de papel y proporcionara servicio a todas las Secciones de la Vicesecretaría.

Y el Archivo nace oficialmente en julio de 1942, ingresando en él las series documentales que ya acumulaban las distintas Secciones, entre ellas la de Censura de libros, cuya preponderancia frente a otras en la generación de documentos explica que inicialmente quisiera llamarse al servicio "Archivo de Censura de Publicaciones de la Vicesecretaría de Educación Popular", rectificándose al poco para dotarlo de una denominación más neutra bajo el nombre de "Archivo General de la Vicesecretaría de Educación Popular" ". A finales de junio de 1942 se acumulaban de forma provisional un total de 17.894 expedientes de la Censura Editorial, junto a un número similar de libros, en espacios ciertamente no muy adecuados para su correcta conservación: "en unos estantes provisionales colocados en una cocina y en unos armarios. Las obras se hallan instaladas en estantes, colocadas en un amplio pasillo. Al disponer de amplio local se procurará hacer lo posible para conseguir una colocación decorosa y definitiva”. En cuanto al estado de conservación de este material acumulado durante cuatro años,

los libros se hallaban amontonados sin orden alguno. Los expedientes en sus armarios sin orden alguno, muchos de ellos trastocados. Se procede a colocar los libros por tamańos y los expedientes por el orden de sus letras respetivas, trabajo previo e indispensable para proceder a la confección del fichero topográfico en la manera que se está estudiando, al propio tiempo que se procura ir instalando la oficina del Archivo con la rapidez que es posible ${ }^{10}$.

Firmaba este informe Ramón Fernández Pousa, del Cuerpo Facultativo de Archiveros, Bibliotecarios y Arqueólogos, a quien se encomendó la je-

9 AGA, Educación, caja 31/07607, exp. "Archivo de la Vicesecretaría de Educación Popular": informe dirigido a la Inspección General de Archivos de 22 de marzo de 1943. El local destinado a Archivo se situaba en el no 2 de la madrileńa calle de Monte Esquinza, sede de la Vicesecretaría, pero con el tiempo se hizo necesario habilitar depósitos adicionales en otros locales de la capital, hasta su centralización total en el nuevo edificio del Ministerio de Información y Turismo, a fines de la década de 1950.

10 Ibidem: Informe de 30 de julio de 1942. 
fatura del Archivo de la Vicesecretaría de Educación Popular en 30 de junio de 1942, permaneciendo en ese cargo hasta febrero de 1963, cuando el embrión había crecido hasta convertirse en el gran Archivo General del Ministerio de Información y Turismo. Este archivero no desconocía los entresijos político-administrativos de la Censura Editorial, pues él mismo había sido censor de libros a las órdenes de Juan Beneyto desde al menos junio de 1939, cuando contaba con treinta ańos; fue cursillista de latín de 1936, Camisa Vieja de las JONS desde 1933, miembro de la Quinta Columna madrileña durante la Guerra Civil, delegado extraordinario de Información e Investigación de FET-JONS para la provincia de Madrid y comisionado para la recogida de libros contrarios al Régimen en la capital recién conquistada ${ }^{11}$. Con tal hoja de servicios, es excusado dudar que se trataba de un militante integrado dentro de la burocracia del partido único, entusiasta y plenamente fiable desde el punto de vista ideológico: en resumen, una persona idónea, con buenas referencias y conexiones, acreedor total de la confianza de sus superiores, que no tuvo problema para hacerse con el puesto una vez salió a "concurso" en $1942^{12}$.

11 AGA, Educación, caja 32/16750, exp. 18469-97: Expediente de depuración políticosocial de Ramón Fernández Pousa (Comisión Depuradora C del Ministerio de Educación Nacional), con abundante información sobre su actuación clandestina en el Madrid asediado. Tampoco perdió el tiempo tras finalizar la guerra: doctorado en Filosofía y Letras en 1940, ingresó en el Cuerpo Facultativo de Archiveros y Bibliotecarios al ańo siguiente; fue profesor adjunto de Historia Universal Antigua y de España de la Facultad de Filosofía y Letras de la Universidad de Madrid; y bibliotecario interino en la Sección de Manuscritos de la Biblioteca Nacional entre abril de 1940 y febrero de 1942. Véase Antonio Ruiz Cabriada, Bio-Bibliografía del Cuerpo Facultativo de Archiveros, Bibliotecarios y Arqueólogos 1858-1958, Madrid, 1958, p. 302.

12 Es interesantísimo el caso de Fernández Pousa como "archivero político". Efectivamente, cuando el Vicesecretario de Educación Popular Gabriel AriasSalgado obtuvo del Ministerio de Educación Nacional, la asignación de un facultativo de Archivos para su organización recordó que era necesario contar con una figura de confianza: "Teniendo en cuenta que el Estatuto de Funcionarios del Partido, de reciente promulgación, exige inexcusablemente la condición de MILITANTE del Partido para determinados cargos, y en atención a la especial documentación del referido Archivo, esta Vicesecretaría le ruega tenga en cuenta su deseo de que el referido cargo sea desempeñado por el Dr. camarada Ramón Fernández Pousa, solicitud que formula teniendo en cuenta otros precedentes 
El personal destinado al Archivo estaba formado en su origen por el propio Fernández Pousa y una mecanógrafa, pero en poco tiempo fue incrementándose hasta contar con una plantilla bastante notable para los paupérrimos parámetros de la época. A fines de 1945 se había incorporado un miembro del Cuerpo Auxiliar de Archiveros, cuatro oficiales, cinco mecanógrafas y un ordenanza. Con su ayuda se llevaron a cabo las tareas iniciales de organización del Archivo, siendo el primer requisito necesario para su puesta en funcionamiento la fijación de unas reglas para el control del flujo documental desde las diversas Secciones que componían las tres Delegaciones de la Vicesecretaría de Educación Popular ${ }^{13}$. De acuerdo a estas reglas, se establecían Archivos en las distintas Secciones, los cuales se encargarían de preparar las transferencias periódicas al Archivo General, luego verificadas con orden mediante el uso de una serie de herramientas normalizadas facilitadas por éste; fundamentalmente las imprescindibles fichas catalográficas de la era preinformática y las relaciones de entrega, a formalizar siempre por duplicado. Con las primeras se debería ir formando un doble fichero, uno en cada Sección y otro en el Archivo General, que permitiera la rápida localización de los expedientes de acuerdo a los criterios de acceso esenciales para el servicio ${ }^{14}$; con las segundas se formalizaba jurídicamente el traspaso de la custodia documental y se iba construyendo un inventario topográfico general del fondo, menos detallado

tales como el relacionado con el Ministerio de Asuntos Exteriores, Consejo de Investigaciones Científicas y otros Organismos": AGA, Cultura, caja 64 Top. 12/25, exp. "Archivo y Biblioteca del Ministerio de Información y Turismo", oficio al Ministro de Educación Nacional de 20 de abril de 1942. Las mayúsculas en el original. Este documento anima desde luego a profundizar en la investigación sobre la política de personal de Archivos durante el franquismo, pues, a la luz de este oficio, es evidente que los "papeles" no podían ser encomendados a cualquiera.

13 Todas las Secciones recibieron unas "Normas" ciclostiladas para la confección de las relaciones de entrega y un "Esquema de clasificación de la documentación en los Archivos de la Sección de la Vicesecretaría de Educación Popular": Memoria del Archivo General de la Vicesecretaría de Educación Popular del año 1943, AGA, Educación, caja 31/07067.

14 Fundamentales, a efectos de comprobar la existencia de antecedentes de censura de obra, eran los criterios de título y número/año de expediente. No hay que olvidar que toda reedición o reimpresión de una obra requería un nuevo paso por la censura; en tales casos se consultaban los antecedentes, los cuales fundamentaban la nueva actuación administrativa. 
en la descripción de contenido. Además del control del flujo documental, el asesoramiento y el suministro continuo de información y documentos a las oficinas productoras, el Archivo General también se encargaba de abastecerlas de otros materiales necesarios para la correcta instalación de los expedientes, como cajas normalizadas ${ }^{15}$, sobres y carpetas.

El caos y desorden iniciales se reflejan claramente en los primeros informes citados, y revelan al mismo tiempo titubeos y sondeos a la hora de proponer una clasificación uniforme y definitiva de los tipos documentales generados por las distintas Secciones ${ }^{16}$, y entre ellas la de Censura Editorial de la Delegación Nacional de Propaganda, que desde el primer día constituyó por su importancia y volumen productivo un conjunto documental diferenciado del resto y fue objeto de tratamiento especial, con un sistema de ficheros exclusivo. Dada su relevancia, Fernández Pousa consideró idóneo realizar subdivisiones en la gran serie de Censura Editorial, asignando, junto al número y ańo de cada expediente, un prefijo alfabético o numérico, correspondiente a las tipologías elaboradas por la propia Sección de Censura, como por ejemplo "Ex" para los expedientes de importación de libros editados fuera de España. Este sistema de clasificación de subseries por letras y números parece abandonarse a partir de 1944, rigiendo desde entonces un criterio uniforme basado en una sola serie, con expedientes clasificados por año y número currens de su tramitación, y descritos mediante tres ficheros: el principal o cronológico, que ordena los expedientes por su número de tramitación; un segundo, auxiliar, que ordena los expedientes por criterio onomástico de autor; y un tercero, también auxiliar, que lo hace por título de la obra ${ }^{17}$. Entre 1937 y 1943

15 Un resto arqueológico de este tipo de cajas primitivas puede todavía contemplarse en la actual signatura AGA 21/07075. Se trata de la cartela exterior de la antigua caja 2178, donde, junto al emblema del yugo y las flechas y el título de "Vicesecretaría - Educación Popular. Archivo General", se consigna el código "Ex", relativo a los expedientes de importación de obras publicadas en el extranjero, el número de la caja y el tramo numérico de expedientes contenidos en ella. Albergaba expedientes de importación de libros tramitados entre junio-julio de 1943.

16 Véase la relación codificada de series en AGA, Educación, caja 31/07067, informe de 30 de julio de 1942, y en el parte trimestral del Archivo de 6 de octubre del mismo año.

17 El estudioso de estos expedientes puede comprobar hoy la presencia de una ficha azul junto al resto de documentos, que ofrece los siguientes datos: Número de 
el expediente de censura se caracteriza por una radical sencillez, expresada en un documento, la "hoja de censura", que permite agrupar, en el recto de un folio, la solicitud propiamente dicha (con los datos del solicitante y de la obra a imprimir), el dictamen de censura y la resolución final, generalmente mediante nota marginal manuscrita, en lápiz rojo o azul ${ }^{18}$.

Además de la serie de Censura Editorial existían otros conjuntos documentales, generados por las Delegaciones de Prensa, Propaganda y Cinematografía, que periódicamente "bajaban” al Archivo de la Vicesecretaría para su custodia y tratamiento: las series de expedientes de censura de producciones cinematográficas y representaciones teatrales y la colección de guiones, los expedientes de autorización de monumentos, carteles y objetos artísticos de la Sección de Plástica, los guiones de comprobación de emisiones de radio de la Sección de Radiodifusión, la correspondencia de las Secciones de Asuntos Generales de las Delegaciones, las consignas de inclusión obligatoria en periódicos y las galeradas intervenidas por la Sección de Prensa, los informes de Auscultación, la correspondencia de la Sección de Ediciones, Editora Nacional e INLE, etc., por citar unos pocos ejemplos de una tipología variadísima y de volumen considerable que ha podido llegar hasta nosotros ${ }^{19}$. Antes de acceder al Archivo, los documentos generados por las oficinas de las Secciones se organizaban en dos grandes conjuntos: por una parte, el de Expedientes, que correspondía a series de tramitación administrativa corriente y gran volumen productivo, como es el caso de la censura, con sus expedientes perfectamente sistema-

expediente, título, autor, editor, año, fecha de entrada, fecha de salida y resolución. No es otra que la ficha que originalmente se encontraba en el fichero principal, y que se insertó en el sobre contenedor del expediente cuando a principios de la década de 2000 se elaboró el actual instrumento de descripción en base de datos IDD (03)050.000. Por tanto, hay que advertir que originalmente los expedientes carecían en su interior de tales fichas.

18 Véase, por ejemplo, el expediente Ext. 7-38, relativo a Mi lucha, de Hitler, en AGA, Cultura, caja 21/07062. El ejemplar que acompañó en su día a este expediente estuvo prestado mucho tiempo a un funcionario de la casa, al que Fernández Pousa no dejaba de recordar la obligatoriedad de su devolución, sin mucho éxito.

19 Accesibles actualmente a través del viejo inventario topográfico IDD (03)049.001, desglosado para la serie de Asuntos Generales de Prensa en el inventario IDD (03)048.000, y para Asuntos Generales de Propaganda en el IDD (03)060.000, ambos manuscritos. 
tizados y numerados; y, por otra, el de Documentos, donde se aglutinan expresiones documentales que no se ajustaban a procedimientos administrativos reglados y repetitivos, sino más bien al imperativo de la comunicación institucional diaria, la resolución de asuntos coyunturales y los pormenores de la estructura organizativa, todo ello reflejado en informes recibidos y enviados, en oficios y notas interiores, y en correspondencia de diverso signo mantenida con instancias públicas y privadas ${ }^{20}$.

Parece evidente que la Sección de Prensa sería la receptora del mayor volumen de papel impreso y la generadora de mayor número de documentos administrativos, aunque es difícil imaginar el funcionamiento de una maquinaria de censura previa, en su versión dura, sin recrear una auténtica inundación de papel en las oficinas centrales y provinciales. No obstante, y comparativamente, contrasta la escasa documentación que de la censura de la prensa periódica ha llegado a nosotros, lo que permite aventurar la hipótesis de prácticas sistemáticas de eliminación de galeradas y otros documentos una vez finalizados los procedimientos de lectura y comprobación. No así la serie de Censura Editorial, cuya conservación permanente o, mejor dicho, su no eliminación a corto plazo, fue considerada conveniente por la Sección de Censura, sobre todo por la necesidad de comprobación de antecedentes ${ }^{21}$. Este hecho fue decisivo para la conformación de la idiosincrasia especial del posterior Archivo General del Ministerio de Información y Turismo, y no es otra que la estructuración del fondo documental en dos grandes conjuntos, delimitados y tratados de forma diferenciada: “a) Documentación general producida por las distintas dependencias [...], desde el mismo momento en que no es necesaria para la cotidiana tramitación administrativa, cualquiera que sea su fecha; b) un grupo de documentos que [...] consideramos de particular interés, constituido por los expedientes enviados por el Servicio de Régimen Editorial"22.

20 AGA, Educación, caja 31/07067, informe de 22 de marzo de 1943.

21 No hay que olvidar que hasta 1966 toda reedición o reimpresión de una obra exigía a las editoriales pasar de nuevo por la censura previa; en tales casos era sistemática la consulta de los antecedentes, que fundamentaban la nueva actuación administrativa; con todo, la comprobación de antecedentes siguió siendo sistemática en la era de la censura voluntaria.

22 AGA, Cultura, caja 96 Top. 12/25: La cita es de 1975, pero ya es completamente válida para la década de 1940. 
Establecidas las bases materiales y normativas para el funcionamiento del Archivo de la Vicesecretaría de Educación Popular, éste comenzó su andadura con satisfacción de las jerarquías y un fuerte ritmo de trabajo, incorporando constantemente nuevas remesas de documentos remitidos por las Secciones, tal y como puede observarse mediante la comparación progresiva de las cifras de ingresos y totales acumulados que refieren las memorias anuales y los partes trimestrales que han llegado a nosotros ${ }^{23}$. A los materiales propiamente documentales se añadiría pronto la gestión de la nueva Hemeroteca Nacional, formada en 1945 a partir de ejemplares duplicados de diarios y revistas ingresados para su control por la Delegación Nacional de Prensa ${ }^{24}$. Esta nueva obligación, que se acumulaba a la necesaria gestión bibliotecaria de la gran masa entrante de libros y publicaciones no periódicas ${ }^{25}$, convertirá enseguida al Archivo en "ArchivoBiblioteca", aunque ello no supuso un desgajamiento de los servicios, pues era necesario combinar las técnicas de la biblioteconomía con las de la archivística para el tratamiento de un material dual tan peculiar como es el de la Censura Editorial. Era una experiencia nueva en la España contemporánea el tratamiento duro de la producción escrita, la centra-

23 La colección de memorias, bastante completa, y de partes trimestrales, en menor medida, en AGA, Educación, caja 31/07067, y AGA, Cultura, caja 64 Top. 12/25, caja 25/19885 y caja 35540 Top. 23/46.

24 La creación de la Hemeroteca Nacional a partir del material acumulado por la censura de la prensa desde 1936 volvió a situar a Fernández Pousa ante los mismos problemas que experimentó en 1942 cuando tuvo que enfrentarse a la organización de los materiales de la censura de libros acumulados sin orden ni concierto desde la guerra. En la memoria del Archivo correspondiente al ańo 1946 se lamentaba de que "el trabajo este año resultó difícil, molesto y poco lúcido por la necesidad de vencer el atasco en Hemeroteca Nacional de todo lo pendiente desde 19361946, en total desorden y bastante suciedad" (AGA, Educación, caja 31/07067). La Hemeroteca Nacional abrió sus puertas al público en 1949, en dependencias alquiladas situadas en la madrileńa calle de Zurbarán, $n^{\circ} 1$. Interesantes fotografías del Centro en AGA, Cultura, caja F/01428, sobre 35.

25 No hay que olvidar que la Sección de Censura de Publicaciones de la Delegación Nacional de Propaganda recibía al menos un ejemplar de cuantas obras se pretendía publicar en España, y además otros cinco de todas las que finalmente se autorizaban e imprimían, a efectos de comprobación posterior. El primero solía quedar en la Sección, remitiéndose los otros ejemplares a la Biblioteca de la propia Vicesecretaría, a la Biblioteca Nacional y a otros organismos. 
lización burocrática del permiso de publicación, la necesidad de leer y enjuiciar previamente todo lo que debía circular. Nunca el documento administrativo y el libro habían convivido tan íntimamente, y este hecho tuvo su reflejo en la organización del Archivo de la Vicesecretaría de Educación Popular y en los combates que tuvieron que librar sus sucesivos responsables, en sus distintas localizaciones institucionales, hasta 1977.

En efecto, los expedientes y los libros que se sometían a la censura se encontraban inicialmente separados, instalándose estos por tamaños con objeto de aprovechar al máximo las estanterías disponibles en las precarias dependencias provisionales que recibió el Archivo; otros ejemplares permanecían en la Sección de Censura, después denominada de Inspección de Libros, a disposición de los funcionarios y lectores (así se denominaban los censores en el vocabulario burocrático). Fernández Pousa, antiguo lector, luchó por reintegrar a sus expedientes los libros o galeradas cuyo formato lo permitieran, pero no siempre tuvo éxito, tal y como escribía en 1948 a propósito de un mandato cuanto menos cuestionable:

"al ordenar que los libros queden en la Sección de Inspección de Libros, se estima se retrotrae la cuestión de la integridad esencial de los expedientes de Censura al año 1942, al ser creado el Archivo y encontrarse con que en más de un ochenta por cien de los casos los expedientes están sin obra impresa, además de faltar muchos en las series, según puede fácilmente comprobarse con el examen de los expedientes anteriores a la creación de este Archivo. Ha sido una lucha constante y dura la mantenida con la Sección de Inspección de Libros para lograr que los expedientes viniesen completos. [...] Igual lucha constante se ha mantenido con esa Sección referente a la devolución de los expedientes y obras que se prestan"26.

He aquí un indicio que nos ayuda a entender la falta parcial de galeradas, manuscritos y ejemplares que puede observarse actualmente en la serie conservada en el Archivo General de la Administración.

26 Oficio al Director General de Archivos y Bibliotecas de 4 de junio de 1948: AGA, Cultura, caja 64 Top. 12/25. El subrayado en el original. Este documento y otro oficio de julio de 1947 conservado en la misma caja prueban que no siempre se cumplieron las normas dictadas inicialmente para regular las relaciones entre el Archivo y las oficinas productoras, y que tal conflicto tuvo consecuencias en el material finalmente conservado. 
En 1945 FET-JONS dejó de administrar la Censura en todos sus ramos, y ésta pasó a depender del católico Ministerio de Educación Nacional, convirtiéndose la Vicesecretaría de Educación Popular en Subsecretaría de Educación Popular ${ }^{27}$, aun cuando siguiera bajo mando de Gabriel Arias-Salgado. Las Delegaciones Nacionales de Prensa y de Propaganda mutaron en Direcciones Generales homónimas. En cualquier caso, los falangistas entusiastas, como Fernández Pousa, que hasta entonces creían firmemente en su poder para orientar la cultura nacional en un determinado sentido ideológico, debieron adecuarse a un nuevo orden en el que sus postulados no tenían mucho futuro tras la derrota de Alemania, situándose ante la disyuntiva de integrarse en la nueva correlación de fuerzas dentro del Régimen o quedar marginados de ella. Fernández Pousa continuó al frente del Archivo, que recibió en septiembre su primera visita por parte del Inspector General de Archivos, Miguel Bordonau. Éste no escatimó elogios para el director y sus empleados, si bien tuvo motivos para enviar una carta particular a Arias-Salgado, exponiéndole algunas cuestiones en materia de locales y personal, y subrayando la necesidad de resolver los problemas existentes para la entrega de libros, revistas y periódicos procedentes de la Censura ${ }^{28}$. Quizá como resultado de esta visita, a principios de 1946 se dictan unas Normas para el Servicio del Archivo de la Subsecretaría de Educación Popular, que dan muestra de la alta confidencialidad y reserva que regían el acceso al fondo documental y de manera especial a la serie de expedientes de Censura Editorial. Entre sus disposiciones merece la pena extractar las siguientes: "Todos los Fondos del Archivo se consideran como RESERVADOS, quedando terminantemente prohibido facilitar dato alguno acerca de los mismos sin orden expresa” (art. 1); "Está rigurosamente prohibido el acceso a las Salas-Depósitos a toda persona que no sea el personal del Archivo" (art. 2); "Queda prohibida la permanencia en las mismas al personal del Archivo fuera del tiempo indispensable en los trabajos asignados a cada uno" (art. 3); "Se establece el préstamo de Obras publicadas sólo para el personal del Archivo y dentro de ciertas limitaciones" (art. 4); "Se prohíbe terminantemente

27 Decreto-ley de 27 de julio de 1945 por el que se organiza la Subsecretaria de Educación Popular en el Ministerio de Educación Nacional: BOE, no 209, de 28 de julio de 1945.

28 AGA, Educación, caja 31/07067. 
la utilización de los ficheros por el personal del Archivo. Todo dato que se necesite será solicitado del Oficial encargado de los mismos" (art. 6); "No se servirá ningún documento o expediente sin el "DESE", precisamente del Jefe del Archivo" (art. 7); "Se prohíbe terminantemente a todo el personal ausentarse de las Dependencias del Archivo sin autorización" (art. 14); "Queda prohibido en absoluto a todo el personal ajeno al Archivo el paso y permanencia en la oficina de catalogación" (art. 15); "Todo incumplimiento o negligencia de las anteriores Normas será considerado como falta gravísima a todos los efectos" (art. 16) ${ }^{29}$. La Dirección del Archivo fue rígida en el cumplimiento de las normas, y de ello da muestra la abundancia de notas de apercibimiento, amonestaciones e incoaciones de expedientes disciplinarios que pueden rastrearse en la documentación de régimen interno conservada ${ }^{30}$. Por supuesto, el carácter reservado de los expedientes excluía por completo cualquier posibilidad de acceso con fines de investigación o distintos a la labor censora. El primer usuario externo a la organización será Manuel L. Abellán, en la segunda mitad de la década de 1970.

En los momentos previos a la creación del Ministerio de Información y Turismo, el expediente de censura editorial presenta ya unas características diplomáticas estables, tanto en sus caracteres externos como internos, que se mantendrán sin cambios de relieve hasta mediados de 1977. El procedimiento administrativo se iniciaba siempre con una instancia en la que se solicitaba autorización para la publicación de la obra, donde se consignaban los datos de la persona física y jurídica solicitantes y los datos de la obra objeto de publicación (título, autor, volumen, formato, tirada, precio y colección). Recibida y registrada de entrada la instancia,

29 Ibidem. Las mayúsculas y subrayados en el original. Hay que recordar que en la primavera de 1942, cuando se estaban realizando las gestiones para el montaje del Archivo, se subrayaba ya el carácter reservado del material y la necesidad de elegir a alguien de confianza, a un "militante", para su gestión.

30 AGA, Cultura, caja 21/05214, que contiene incidencias de empleados del Archivo y de la Hemeroteca Nacional, incluido un expediente de Emilio Romero, que pasó por este último establecimiento en 1952; y AGA, Cultura, caja 35540 Top. 23/46, donde pueden encontrarse notas bastante amenazadoras del Director a sus empleados, como ésta de 1 de diciembre de 1959: "Le ruego tenga la amabilidad de justificar debidamente ante esta Dirección su permanencia en Secretaría a las 4,30 del día de hoy, cuando esto está reiterada y rigurosamente prohibido". 
acompañada del ejemplar (o ejemplares) de la obra correspondiente, los siguientes pasos en la tramitación del procedimiento se expresaban documentalmente en un impreso normalizado, con forma de cuaderno de cuatro páginas, que estructuraba el iter administrativo en varias fases: en la primera página del cuaderno se volvían a inscribir los datos básicos de la obra, ya provista de un número de expediente (currens de tramitaciónaño), existiendo en la parte inferior espacios para notas de comprobación de antecedentes y asignación de lector; la segunda página se reservaba para el informe de censura propiamente dicho, en forma de cuestionario que debía rellenar el lector, con preguntas directas encaminadas a esclarecer si la obra atacaba al dogma, a la Iglesia y sus ministros, a la moral, al Régimen y sus instituciones y colaboradores, seguidas de un "resultando" o valoración final ${ }^{31}$; la tercera página incluía los proveídos administrativos derivados del informe anterior, iniciándose con la propuesta (de autorización, autorización con tachaduras, denegación, silencio administrativo, etc.) del Jefe de Negociado, a su vez elevada a la conformidad del Jefe de la Sección, y finalmente del Director General, cuya firma constituía la resolución final del expediente; la última página informaba de la diligencia de depósito de los ejemplares exigidos a la editorial para verificar que la publicación saliera de las prensas de acuerdo al dictamen gubernativo. En muchos casos, un ejemplar en forma de galeradas, mecanoscrito o simi-

31 Este cuestionario se mantuvo prácticamente invariado durante todo el franquismo, incluso tras la promulgación de la Ley de Prensa e Imprenta de marzo de 1966, que transforma la censura previa obligatoria, imperante desde el comienzo de la Guerra Civil, propia de un estado de excepción, en una censura voluntaria, pretendidamente más abierta y adecuada a un régimen estabilizado política y socialmente. Sí que puede observarse, a raíz de la nueva Ley, una variación en los formularios de solicitud y en la primera hoja del cuaderno, según se trate de una solicitud de consulta voluntaria (CV en la ficha), de depósito (D) o de autorización de publicaciones infantiles y juveniles (I), ramo en el que se mantiene la censura previa obligatoria. A la hora de formalizar el informe de censura se daba cierta flexibilidad y libertad de acción a los censores, que en muchas ocasiones optaban por no cumplimentar el cuestionario, limitándose a elaborar un dictamen de mayor o menor enjundia en el espacio reservado para la valoración final. En otras ocasiones, el dictamen superaba ampliamente el espacio dispuesto en la segunda página y los censores se explayaban en folios o cuartillas adicionadas al cuaderno. La valoración crítica del lector no tenía efectos vinculantes, y en ocasiones se podía solicitar una o más lecturas a otros censores de la plantilla. 
lar, acompaña a los documentos básicos del expediente; pero no siempre, pues las frecuentes inundaciones acaecidas en los diversos depósitos y los conflictos sobre la custodia que enfrentaron al Archivo con la oficina productora causaron pérdidas. Todo ello se instalaba en un sobre de papel de estraza con membrete, en cuya superficie se indicaba de forma manuscrita el número y año del expediente, y donde también se estampaban notas relativas a existencia de galeradas, ubicación de ejemplares editados (por ejemplo, mediante la expresión "Obra en Biblioteca”, indicando que uno de los ejemplares ya publicados había pasado a formar parte de los fondos de la Biblioteca de la Subsecretaría de Educación Popular, posteriormente Biblioteca General del Ministerio de Información y Turismo) y otros pormenores.

Éstos son los componentes básicos de un expediente de censura editorial ordinario y, sobre todo, del que ha sido resuelto positivamente en primera instancia. Ahora bien, cuando el expediente no se resolvía satisfactoriamente y se exigían correcciones y tachaduras, o bien se denegaba la obra y la editorial se atrevía a forcejear con el aparato burocrático para lograr un resultado alternativo, aparecen otros documentos, obligatorios o complementarios, que pueden ser de lo más dispar: cuaderno adicional para el expediente de recurso de revisión, oficios y notas interiores, informes ampliatorios, cartas y nuevas instancias del solicitante, correspondencia oficial y particular entre los representantes de la editorial y altos cargos de la Administración, cartas de los propios autores, notas y recortes de prensa, despachos diplomáticos, informes y notas de los servicios de información, fotocopias de sentencias y autos judiciales, etc. En los casos más complejos, y por tanto más interesantes, el expediente revienta el envoltorio del sobre y el formato en cuarto y se organiza en forma de voluminoso expediente, más bien dossier, en folio ${ }^{32}$.

A mediados de 1951 el Régimen volvía a reordenar la estructura del Estado, centralizando en el nuevo Ministerio de Información y Turismo todas las funciones de control y orientación de los medios de comunicación, la producción editorial, el teatro, el cine, los espectáculos y, novedad, la

32 Véase, por ejemplo, el exp. 11428-73, relativo a Si te dicen que caí, de Juan Marsé, en AGA, Cultura, caja 73/03522, donde se puede encontrar un exhaustivo seguimiento de la repercusión de la obra en la prensa periódica y correspondencia del propio autor con Ricardo de la Cierva, a la sazón Director General de Cultura Popular. 
actividad turística, que hasta entonces seguía dependiendo del Ministerio de la Gobernación ${ }^{33}$. Se iniciaba la etapa más larga y definidora de la gran serie de Censura Editorial, cuyos expedientes serán tramitados a partir de ahora por la Dirección General de Información a través de la Sección de Inspección de Libros y Publicaciones no periódicas, estructurada a su vez en diversos Negociados. La custodia seguirá encomendada a Fernández Pousa, quien, trimestre a trimestre, año a ańo, iba registrando en sus partes y memorias el crecimiento de la masa documental a su cargo, estimada en julio de 1956 en 11.883 unidades de instalación o 3.316.500 expedientes, de los cuales varias decenas de miles pertenecían al conjunto especial de la Censura Editorial ${ }^{34}$. Bajo su mando se encontraba, por una parte, el Archivo y Biblioteca Generales del Ministerio, dependientes de los Servicios Centrales de la Subsecretaría, y, por otra, la Hemeroteca Nacional, que se mantenía adscrita a la Dirección General de Prensa, como principal proveedora de fondos. La plantilla estaba formada por el director facultativo Fernández Pousa, el auxiliar Carlos Ibáñez Guillén ${ }^{35}$, ambos funcionarios archiveros, y un jefe de administración, 6 jefes de negociado, 25 auxiliares y 8 ordenanzas ${ }^{36}$. La sede de la Dirección y Secretaría del Archivo General

33 Decreto-ley de 19 de julio de 1951 por el que se reorganiza la Administración Central del Estado: BOE, no 201, de 20 de julio de 1951. Arias-Salgado será responsable de esta cartera hasta su sustitución por Fraga en 1962.

34 No es sencillo cuantificar el total exacto de expedientes tramitados desde los orígenes de la Censura. Puede realizarse una aproximación a partir de las memorias anuales y partes trimestrales de trabajo y con el inventario IDD (03)050.000, actualmente disponible en el AGA. A modo de ejemplo, valga el dato de que los expedientes de los años 1944-1947 transferidos al Archivo sumaban un total de 18.578 unidades: AGA, Educación, caja 31/07067, parte de trabajos del primer trimestre de 1952. A fines de 1962, el Archivo General del Ministerio albergaba los expedientes tramitados entre 1937 y 1953.

35 Nacido en Valbona (Teruel) en 1920, ingresó en el Cuerpo de Auxiliares de Archivos, Bibliotecas y Museos el 16 de mayo de 1941; tomó posesión en el Archivo General de la Subsecretaría de Educación Popular, procedente del Archivo del Jardín Botánico de Madrid, el 22 de marzo de 1946. Continuará en el Archivo General del Ministerio de Información y Turismo y será en 1978 el primer director del Archivo Central del Ministerio de Cultura, tras la extinción del anterior.

36 Esta relación de empleados funcionarios y laborales, incluida en la memoria anual de 1952, engloba a todo el personal adscrito a los tres servicios: AGA, Educación, caja $31 / 07067$. 
del Ministerio, junto a los ficheros, quedó radicada en la Hemeroteca Nacional, en Zurbarán, 1, existiendo además depósitos en dependencias situadas en Monte Esquinza 2 (sede oficial del Ministerio), en Castellana 42, en Ramón de la Cruz 4 y en O’Donnell 27.

Estos depósitos dispersos del Archivo General se centralizarán posteriormente en una única sede, en el nuevo edificio del Ministerio de Información y Turismo, hoy Ministerio de Defensa, sito en Castellana 109, por entonces Generalísimo 39. Entre fines de 1960 y principios de 1962 se procedió al traslado de todos los nidos documentales dispersos a las nuevas instalaciones del Archivo General, nada acertadas desde luego, pues los depósitos fueron situados en el refugio antiaéreo subterráneo del enorme Ministerio, sufriendo de inmediato cuatro inundaciones, con gran daño para la documentación, que quedó diezmada ante la aparente indiferencia de los altos funcionarios encargados del régimen interior del Departamento ${ }^{37}$. Es posible que la catástrofe acuática, conocida por todos los funcionarios de la casa, explique la renovación de la reticencia de la Censura Editorial, ahora denominada formalmente Sección de Orientación Bibliográfica, a remitir sus expedientes finalizados, galeradas y obras editadas al Archivo General. La Sección se las arregló para anular en la parte que le tocaba una Orden Ministerial de 26 de julio de 1962 que exigía la centralización en el Archivo General de toda la documentación generada por el Ministerio. Son muy interesantes las razones aducidas por la Sección, que iluminan sus procedimientos de trabajo: "El Archivo de Expedientes de Orientación Bibliográfica no es un Archivo administrativo cuya documentación pierda vigencia con el tiempo"; "Los Expedientes que lo forman son la médula del Servicio de Orientación Bibliográfica, sin cuyo concurso se desarticularía su funcionamiento y hasta se paralizaría";

37 Véase el parte extraordinario, firmado por el auxiliar Carlos Ibáñez en 30 de junio de 1962, donde se relacionan casi un millar de cajas destruidas por efecto del agua. Estas bajas corresponden casi perfectamente a las consignadas en el actual inventario IDD (03)049.001, que da acceso a las series de las Delegaciones Nacionales/ Direcciones Generales de Prensa, Propaganda y Cinematografía (décadas de 1940 y 1950) que han llegado hasta nuestros días: AGA, Cultura, caja 35540 Top. 23/46. Las filtraciones de agua y consiguientes destrucciones por humedad continuarán en los años siguientes; además, el depósito parecía disponer de un amplio pasillo, que será utilizado para almacén de mobiliario. Las oficinas de Dirección, Secretaría, Ficheros y espacios de trabajo y lectura se situarán tres pisos más arriba. 
"Los Informes de los Lectores que deciden la resolución del Expediente, salvo superior criterio, no prescriben y son necesarios como complemento del Fichero que registra tan solo la terminación del Expediente, pero no las causas determinantes, y los mismos Lectores necesitan comprobar los motivos de la decisión"; "Las Obras Editadas forman parte integrante del Expediente, ya que su destino no es una Biblioteca, sino un Archivo, y al extraer la Obra los Expedientes quedarían mutilados, siendo imposible comprobar en el momento preciso la exactitud de sucesivas ediciones o reimpresiones"; "El Negociado de Importación tiene una misión cara al Extranjero que se vería imposibilitada, al no contar con los antecedentes, dada la rapidez y agilidad que requiere el interés de los Importadores".

El Secretario General de Información apuntalaba este informe con los siguientes razonamientos: "En el Archivo General nuestros fondos serán uno de tantos conjuntos a los que se prestaría la misma atención que a otros cuya vitalidad fuese nula, y la experiencia demostró en el pasado que los antecedentes de Expedientes anteriores al año 1953 que obran en ese Archivo General no fueron facilitados cuando eran necesarios, procediéndose a una nueva lectura, con el peligro de incurrir en contradicciones y, sobre todo, empleando más tiempo y esfuerzo"; "Diariamente por teléfono se solucionan desde este Archivo [el de la Sección de Orientación Bibliográfica] dudas en el Registro, o el Fichero, respecto a señas, títulos, nombres que figuren en la instancia, además de consultas que no requieren el envío del Exp. [sic]. El Servicio de Expedientes es en la actualidad rápido y eficaz, como puede comprobarse, y está rigurosamente vigilado, tanto a la entrega como a la devolución"; "También se da el caso de cambio o préstamo de originales a los autores y editores por causas justificadas que se resuelven sin pérdida de tiempo para el solicitante"; "Teniendo en cuenta que la Sección de Orientación Bibliográfica tiene un deber para con el público en general y para los Editores, libreros o importadores en particular, todo lo que sea facilitar los trámites resulta aconsejable, pudiendo fácilmente comprobarse que el sistema actual de funcionamiento del Archivo facilita la consulta de antecedentes, aun los más antiguos"; "Otro problema se planteará al enviar casi todos los fondos actuales al Archivo General. Puede[n] observarse en el cuadro que incluyo los trámites sucesivos a que está sujeto un expediente que, constando de instancia y original, termina finalmente con una documentación complementaria, 
cuya incorporación al Expediente se realiza por etapas, sin sujeción a plazos. Constantemente hay un volumen considerable de documentación para intercalar en los Expedientes, labor que se realiza a diario para tener los datos actualizados" 38 . Por Orden Ministerial de 26 de noviembre de 1962 se excluía a los expedientes de Censura Editorial de su centralización en el Archivo General (al menos temporalmente, pues poco tiempo después se reanudarán).

Tras este varapalo, Fernández Pousa abandonó la dirección del Archivo y Biblioteca Generales del Ministerio, dedicándose exclusivamente a la Hemeroteca Nacional $^{39}$. El 13 de febrero de 1963 le sustituye Marcelina Íniguez Galíndez, de 54 años y vocación bibliotecaria, quien mantendrá en lo sustancial la dinámica de trabajo de su antecesor; quizá con menos mano de hierro, pero con la misma capacidad de trabajo y eficacia ${ }^{40}$. La memoria del Archivo y Biblioteca Generales correspondiente al año 1964 informa de una considerable reducción de plantilla a sólo 11 personas, tras el desgajamiento de la Hemeroteca Nacional. El Archivo contaba con 16.750 unidades de instalación, pero en esta numeración no se incluye la serie de Censura Editorial, pues, como ya se ha dicho, formaba conjunto documental especial, con signaturas y fichero particulares. Los instrumentos de descripción que daban acceso a los fondos documentales son esencialmente los mismos que se arbitraron desde su creación en 1942: 1) "Fichero orgánico (Comprende las fichas de la documentación enviada por las distintas Secciones del Ministerio, agrupada por legajos). En el año 1964 se han catalogado 2.746 legajos"; 2) "Fichero de Personal (Se incluyen en él las fichas de los expedientes de Personal que ha causado baja en el Departamento)"; 3) "Fichero de Orientación Bibliográfica [esto es, de la Censura Editorial] (en él se catalogan las fichas de los expedientes de esta Sección, señalando autor y título de la obra objeto del expediente,

38 AGA, Cultura, caja 35539 Top. 23/46. Las mayúsculas y subrayados en el original.

39 Permanecerá en dicho puesto hasta su jubilación en diciembre de 1979.

40 Oriunda de Madrid, ingresó en el Cuerpo Facultativo de Archiveros y Bibliotecarios el 2 de junio de 1941, si bien ya había desempeñado servicios de forma interina. Durante las décadas de 1940 y 1950 sirvió fundamentalmente en la Biblioteca Nacional, donde fue responsable de Exposiciones. Tenía experiencia en el exterior, contratada por el Gobierno de Colombia para servicios técnicos en la Biblioteca Nacional de Bogotá. Fue sustituida en mayo de 1972, al frente del Archivo General del Ministerio de Información y Turismo por Margarita Navarro Martorell. 
cuyo número de orden se indica en la misma). En el año 1964 se han hecho 7.815 fichas de expedientes que corresponden a los años 1953 y parte de 1954"; 4) "Registro de Entrada de Fondos (En él se registran las relaciones de documentos enviados por las distintas Secciones del Departamento). El número total de relaciones registradas es de $198^{\prime 41}$. Entre 1964 y 1970 tuvieron lugar las transferencias más voluminosas desde las Secciones del Ministerio hasta el Archivo General, que a principios de aquel año albergaba un total de 55.469 unidades de instalación, de las cuales 20.021 pertenecían a la Censura Editorial, más de un tercio del total conservado. Al comenzar 1971, el depósito, con cerca de 9 kilómetros lineales de estantería, estaba saturado en su totalidad, incapaz por tanto de aceptar nuevas remesas ${ }^{42}$.

Durante la década de 1960, y a raíz del crecimiento exponencial de la documentación transferida al Archivo, fruto a su vez de la fuerte expansión de la actividad del Ministerio en los años del desarrollismo y el boom tu-

41 AGA, Cultura, caja 35541 Top. 23/46. Hay que puntualizar que el fichero de Orientación Bibliográfica creado en el Archivo es independiente del conjunto de ficheros e instrumentos generados en la propia Sección para el control y servicio de sus expedientes. Fue un hándicap constante el mantenimiento actualizado de ese primer fichero por parte del Archivo General, considerado fundamental por la Inspección General de Archivos, que en el acta de la visita realizada el 18 de octubre de 1966 constataba: "El Sr. Inspector [...] consideró de urgente necesidad la continuación del fichero de expedientes de censura de libros, interrumpido desde el ańo 1954, ya que la copiosa entrada de los mismos (en un ańo ingresarán 70.000 expedientes) impide que el personal actual (totalmente insuficiente), pueda dedicarse a esta tarea": AGA, Cultura, caja 96 Top. 12/25.

42 AGA, Cultura, caja 25/19885: Memorias anuales del Archivo-Biblioteca de los años 1970 y 1971. En cuanto a las condiciones de trabajo en el Archivo, seguían siendo incómodas, "ya que solamente existe un pequeño espacio, un despacho aislado del depósito general, que permite realizar en el local del Archivo la labor de manipulación de expedientes para la confección y distribución de legajos, mientras que toda la labor técnica (confección de fichas, listas, etc.), así como el servicio del Archivo, tiene que realizarse en la Biblioteca General, situada tres pisos más arriba y sin ninguna comunicación directa, y ya no digamos mecánica, entre los dos locales [...]. // En cuanto a la instalación del Depósito General del Archivo, es completamente deficiente en lo tocante a iluminación y comunicaciones interiores, las cuales no existen. Asimismo, el pequeńo despacho en que se realiza la manipulación de los fondos carece de la menor calefacción...”: AGA, Cultura, caja 96 Top. 12/25, informe de 1975. 
rístico, se detectan los primeros planteamientos destinados a implementar acciones de valoración y eliminación de series documentales generadas por el Departamento, cuya acumulación progresiva en los depósitos de custodia de las oficinas y en el propio Archivo General comenzaba a preocupar a su directora. Efectivamente, en junio de 1966 Marcelina Íniguez se dirigía a la Oficialía Mayor del Ministerio en estos términos: "Ante la creciente afluencia de documentación enviada por los distintos Servicios del Departamento, nos vemos precisados a informar a V.I. de la conveniencia de hacer un análisis de la documentación existente para determinar, por el valor de los documentos, el posible interés administrativo de los papeles, ya que la valía histórica de los mismos corresponde determinarla posteriormente a la Dirección General de Archivos y Bibliotecas". Por lo que atañe a los expedientes de la Censura Editorial, reafirmaba su valor único y tratamiento diferenciado: "Existiendo en nuestro Archivo General toda la documentación de la producción bibliográfica española desde el año 1938 hasta el 1958 (última documentación recibida), consideramos que esta documentación, por su carácter especial, no puede, en ninguna forma, ser objeto del citado expurgo y, en su consecuencia, aconsejamos el traslado en depósito, al Archivo Histórico Nacional, de la de diez años (1938 a 1947), con el fin de dejar espacio libre a los nuevos fondos de esta Sección, que ingresan diariamente, y previa autorización de la Dirección General de Información, que es la que consulta con frecuencia los indicados documentos”. En respuesta, el Oficial Mayor propondrá la constitución de una comisión formada por Jefes de Sección de la Subsecretaría, la Secretaría General Técnica y las distintas Direcciones Generales del Ministerio para proceder a la "delimitación de aquellos documentos cuya destrucción puede proponerse a la Dirección General de Archivos y Bibliotecas" ${ }^{43}$. Dado que en las memorias anuales de 1966 y 1967 no hay referencias a la puesta en marcha de tal comisión, es de creer que la propuesta quedara en agua de borrajas ${ }^{44}$.

43 AGA, Cultura, caja 96 Top. 12/25. Los subrayados en el original. Ese proyecto de traslado de los expedientes acumulados de la Censura Editorial al Archivo Histórico Nacional, donde quedarían depositados, dado su carácter reservado, con las restricciones que estableciera el organismo productor, se volverá a considerar a principios de 1971. La misma situación de saturación crónica del Archivo Histórico Nacional imposibilitó llevarlo a cabo.

44 El año 1967 es importante para los Archivos Centrales ministeriales pues se 
Si las medidas de valoración y eliminación documental no fueron ejecutadas, o siquiera discutidas, ello se debió a que al poco tiempo apareció disponible un excelente aliviadero en Alcalá de Henares, donde se estaba construyendo por el Ministerio de Educación y Ciencia, con cargo a los créditos del II Plan de Desarrollo, un nuevo edificio para Archivo General de la Administración Civil del Estado ${ }^{45}$. En 1971 fueron depositados provisionalmente en el vetusto Convento de Santa Úrsula de Alcalá 9.006 legajos y 1.210 libros registro, ingresando definitivamente en noviembre de 1972 en el Archivo General de la Administración, cuando las obras estaban próximas a finalizar. Se trataba de los documentos más antiguos custodiados en el Archivo General del Ministerio de Información y Turismo, del período 1937-1960. No obstante, la primera gran remesa de expedientes de Censura Editorial se verificó en noviembre de 1973: 19.036 legajos, correspondientes al período 1937-1963. Estos alivios crearon espacio en Madrid para que la Sección de Ordenación Editorial de la Dirección General de Cultura Popular y Espectáculos (sucesora de la antigua Dirección General de Información) pudiera "bajar” al Archivo Ministerial diez años más de expedientes. La siguiente gran transferencia al Archivo General de la Administración tuvo lugar en enero de 1976: 14.078 legajos de documentación general y los expedientes de Censura Editorial del año 1964, seguidos en marzo de 1977 por los tramitados entre 1965 y 1968, albergados actualmente en 3.753 cajas.

Justo entre estas dos últimas transferencias se sitúa el primer acceso a la Censura Editorial con fines de investigación, por parte del barcelonés Manuel L. Abellán, profesor del Instituto de Romanística de la Universidad de Ámsterdam, fallecido hace pocos años, quien, contra todo pronós-

establece, para todos ellos, su dependencia directa de la Secretaría General Técnica de cada Departamento, junto a Bibliotecas y Centros de Documentación, de acuerdo al artículo 15, letra b, del Decreto 2764/1967, de 27 de noviembre, sobre reorganización de la Administración Civil del Estado para reducir el gasto público: BOE no 284, de 28 de noviembre de 1967.

45 Carmen Pescador del Hoyo, del Archivo Histórico Nacional, veterana del desaparecido Archivo General Central, fue la encargada de regresar a Alcalá de Henares para realizar los preparativos de recepción de las primeras transferencias desde los Archivos Ministeriales. Su trabajo tuvo que realizarse en condiciones penosas, con las obras no terminadas todavía, tal como se refiere en un emotivo informe del año 1975: AGA, Cultura, caja 66/21595, exp. "Archivos Ministeriales". 
tico, consiguió en septiembre de 1976 autorización oficial para acceder a los expedientes “vivos” de la Censura Editorial. Las condiciones eran las siguientes: no podía fotocopiar nada y no podía mencionar la identidad de los lectores. Entre septiembre y octubre de 1976 realizó sus consultas, con ayuda de magnetófono, en la sede del Ministerio de Información y Turismo, y entre junio y julio de 1977 en el Archivo General de la Administración, donde ya pudo solicitar fotocopias. Estas consultas le aportaron materiales suficientes para la redacción de su pionera obra Censura y creación literaria en España (1939-1976). Quizá no serían tan relevantes los entresijos de una investigación personal como la de Abellán si no fuera porque, en agosto de 1977, dirigió una carta a Pío Cabanillas, primer Ministro de Cultura, denunciando hechos graves relativos a la custodia e integridad de la serie de la Censura Editorial en sus documentos generados entre 1964 y 1969. Concretamente, acusaba a los funcionarios de la Sección de Régimen Editorial de haber "expurgado" en octubre de 1976 el contenido de gran cantidad de los expedientes interesados. Solicitado informe al Comisario Nacional de Archivos sobre este particular (los expedientes de 1963-1968 objeto de sospecha ya se encontraban en Alcalá de Henares), se contestaba en sentido negativo en septiembre de 1977, adjuntando informe de la directora del Archivo General de la Administración, quien no observó alteración digna de nota ni queja alguna de Abellán relativa al contenido o estado de los expedientes.

Pío Cabanillas instó a Abellán ese mismo mes a aportar pruebas o datos concretos de las extracciones mencionadas, contestando éste el 26 de septiembre mediante carta en la que citaba los casos de siete expedientes concretos en los que había advertido faltas ${ }^{46}$. Parece ser que la última

46 Se trata de los expedientes 2725-65 (Camilo José Cela, Nuevas escenas matritenses, Alfaguara), 632-66 (Isaac Montero, Alrededor de un día de abril, ed. autor), 3074-66 (Alfonso Sastre, Obras Completas, Aguilar), 824-66 (José Ma Castellet, Un cuarto de siglo de poesía española, Seix-Barral), 129-66 (J.A. Zunzunegui, Un hombre entre dos mujeres, Noguer) y 3170-65 (Benvenuto Terracini, Lengua libre y libertad lingüistica, Ciencia Nueva) y 3496-68 (Olao Conforti, Guadalajara. La primera gran batalla de la Guerra Civil española, Oikos Tau). Examinado el contenido actual de estos expedientes, francamente no parecen advertirse las carencias evidentes anotadas por Abellán, quien habla en ocasiones de que "falta todo". Una comparación entre el contenido de los expedientes del AGA y el material transcrito o fotocopiado por el propio autor, disponible hoy en el archivo personal depositado en el CRAI 
misiva de Abellán no obtuvo respuesta satisfactoria, lo que posiblemente explique que Diario 16 publicara entre el 16 y el 18 de marzo de 1978 tres artículos consecutivos sobre el presunto expurgo de 61.401 expedientes, circunstancia ésta totalmente inverosímil. La campańa de prensa volvió a encender las alarmas y generó una nueva ronda de informes oficiales, entre los que quizá merezca la pena destacar uno, sin fecha, pero elaborado en los días inmediatos a la publicación de los artículos, donde parece aclararse lo que sucedió en el Ministerio de Información y Turismo en septiembre-octubre de 1976, pues se afirma que, por disposición del Director General de Cultura Popular,

se determinó que de los expedientes que se sirvieran a dicho señor se desglosaran los papeles que no fuesen oficiales (notas, opiniones sin firmar, cartas particulares, etc.). Orden que se ha hecho efectiva con respecto a los expedientes que todavía están en el Servicio y no han sido llevados al Archivo General. Parece que [en] dicho Servicio, ante la orden dada y aludida, desglosaron estos papeles, ignorando que ya se había hecho por parte del Sr. L. Abellán una primera lectura. La actitud del referido investigador de registrar en el dictáfono sus investigaciones molestó, al parecer, al Servicio; y por otra parte, el propio investigador también se disgustó, pues observó que de los expedientes que le servían habían sido desglosados algunos documentos. Como consecuencia de todo ello, el Sr. L. Abellán abandonó la investigación después de haberla realizado durante unas semanas ${ }^{47}$.

Dado que muchos de los documentos que Abellán considera perdidos se encuentran hoy en sus expedientes, parece evidente que se procedió a su reintegración en un momento posterior.

En cualquier caso, se trata de un episodio lamentable, fruto de la ausencia de una mínima reglamentación del derecho de acceso a los documentos administrativos en una época de gran discrecionalidad gubernativa.

Biblioteca del Pavelló de la República de Barcelona, contribuiría a esclarecer este asunto.

47 Toda la correspondencia e informes que generó esta denuncia se han conservado en un expediente formado por el Ministerio de Cultura conservado en AGA, Cultura, caja 79826 Top. $73 / 51$. 
A principios de la década de 1970, los expedientes de Censura Editorial parecían testigos molestos de un pasado ya percibido como incómodo, indignos de ser utilizados como fuente de investigación histórica. Merece la pena rescatar una opinión oficial que sobre este asunto se vertía a principios de 1971, a propósito del ya mencionado proyecto de trasladar los expedientes al Archivo Histórico Nacional, que por entonces era el gran centro de la investigación histórica española:

El proyecto de enviar [...] los expedientillos de la censura de libros de los ańos 38 a 52, francamente no me parece acertado. La documentación de la censura de libros muchas veces consistió exclusivamente en una instancia y una firma aprobatoria y, con frecuencia, en notas breves de los censores de turno. Un expediente de censura no ha sido frecuentemente más que la expresión de un acto de voluntad administrativa sin ninguna de las formalidades, alegatos y considerandos que pudieran tener interés histórico. Del archivo de la antigua censura no creo que haya nada útil para un historiador, y sí, en cambio, anécdota menuda para aliento de insanas curiosidades y malicias ${ }^{48}$.

Por el contrario, la sucesora de Marcelina Íniguez al frente del Archivo y Biblioteca Generales del Ministerio, Margarita Navarro Martorell, siguió defendiendo la idiosincrasia especial del fondo documental-bibliográfico de la Censura como un tesoro de especial riqueza informativa ${ }^{49}$.

48 Carta de Enrique Thomas de Carranza, Director General de Cultura Popular, al Secretario General Técnico del Ministerio de Información y Turismo (10 de febrero de 1971): AGA, Cultura, caja 96 Top. 12/25.

49 "Con arreglo a las disposiciones legales vigentes (Ley de Prensa, 19/III/66) compete al Servicio de Régimen Editorial, dependiente de la Dirección General de Cultura Popular y Espectáculos del Ministerio de Información y Turismo, la Consulta Previa Voluntaria y el Depósito Previo Obligatorio de todas las publicaciones no periódicas, editadas o distribuidas en Espańa; uno de cuyos ejemplares pasa automáticamente a engrosar la Biblioteca General de dicho Ministerio. // De ahí la importancia y características especiales del Archivo y Biblioteca Generales del Ministerio de Información y Turismo; ya que en el primero se conservan los expedientes, historiales, $\mathrm{y}$ en muchas ocasiones galeradas, de toda publicación no periódica editada o distribuida en Espańa desde el año 1937 hasta el momento actual, mientras que las obras bibliográficas que acompañan este historial nutren su biblioteca. Es decir, que 
Disuelto el Ministerio de Información y Turismo en julio de 1977 y extinguida formalmente la censura voluntaria ${ }^{50}$, la última transferencia de expedientes de Censura Editorial, procedente del Archivo Central del Ministerio de Cultura, heredero documental de su predecesor, se completó en enero de 1984, comprendiendo los expedientes tramitados entre 1968 y 1983, cerrándose entonces el ciclo de transferencias ${ }^{51}$. En Alcalá se centralizaba por primera vez la serie completa de la Censura Editorial, formando uno de los conjuntos documentales más voluminosos conservados en el Archivo, con un total de 23.343 cajas normalizadas, albergadas en los módulos de depósito 21, 66 y 73 . A principios de la década de 2000 se procedió a la creación de una base de datos, actual IDD (03)050.000, con el objetivo de sustituir el gran fichero cronológico por una herramienta informática que permitiera la búsqueda por diversos criterios, como autor, obra, editorial o número de expediente/año, y que actualmente cuenta con más de 460.000 registros descriptivos. Desde entonces se ha convertido en una de las fuentes documentales más consulta-

el conjunto Archivo-Biblioteca Generales del Ministerio de Información y Turismo viene a ser como un depósito de la historia de la bibliografía española de los últimos casi cuarenta años": AGA, Cultura, caja 96 Top. 12/25, informe sin fecha, pero de febrero-marzo de 1975, dirigido a la Inspección General de Archivos.

50 Real Decreto-ley 24/1977, de 1 de abril, sobre libertad de expresión: BOE, no 87, de 12 de abril de 1977. Este hecho tiene su expresión diplomática en una simplificación mayor del expediente, con la eliminación de la labor de crítica del lector, que a partir de ahora se limitará a marcar con una $\mathrm{X}$ dos de cuatro casillas en una tarjeta: las dos primeras tendentes a verificar si procedía o no adoptar las previsiones del ya modificado artículo 64 de la Ley de Prensa e Imprenta, y las dos siguientes a indicar si se habían cumplimentado o no los requisitos formales de depósito por parte del solicitante. El último expediente de depósito, tramitado por el Servicio de Promoción Editorial de la Dirección General del Libro y Bibliotecas del Ministerio de Cultura, última oficina encargada de este menester, corresponde a la Memoria de Actividades de 1982 del Servicio de Extensión Agraria de la Consejería de Agricultura y Pesca del Gobierno Autónomo de Canarias: AGA, Cultura, caja 73/08146, exp. 3453-83.

51 Véase la nota 4. Hay que advertir que los expedientes del período 1968-1980 fueron reintegrados con sus "Historiales", es decir, con los informes de los lectores, que por entonces se desglosaban de sus expedientes, siendo enviados al AGA por separado, donde fueron completados. Por su parte, los expedientes de Importación de Libros, que a partir de 1961 forman un conjunto aparte de la serie general de la Censura Editorial, ingresaron en el AGA en diciembre de 1986. Forman una serie de 183 cajas, accesible a través del inventario IDD (03)052.117. 
das por la comunidad científica, existiendo prácticamente a diario una o más investigaciones activas en la Sala de Consulta del Archivo General de la Administración dedicadas a la Censura Editorial, tanto de usuarios nacionales como extranjeros, enfocadas desde diversas metodologías y amplitudes: desde el estudio de la censura recaída sobre la obra de un autor concreto hasta la recepción en España de las traducciones de un género literario en particular, por citar dos ejemplos al azar; investigaciones que ya forman un importante corpus historiográfico, en forma de libros, artículos e incluso publicaciones periódicas y monográficas especializadas, a tener en cuenta para futuros trabajos.

En cuanto al destino final de la Biblioteca del Ministerio de Información y Turismo, su fondo permaneció en el Ministerio de Cultura hasta que, a mediados de la década de 1980, los ejemplares procedentes de la Censura Editorial, incluidos los del Negociado de Importación, fueron trasladados a la Biblioteca Pública del Estado "Miguel Alvar", en la Calle Azcona 42 de Madrid, donde constituyen una colección especial denominada "Fondo de Censura" o "Fondo del Ministerio" 52.

52 "Biblioteca Pública del Estado Manuel Alvar", p. 6. Disponible en http://www. madrid.org/bibliotecamanuelalvar [15 de julio de 2017]. 